\title{
Research of power fuel low-temperature vortex combustion in industrial boiler based on numerical modelling
}

\author{
K.Y. Orlova ${ }^{1, *}, B . V$. Lebedev $^{1}$ \\ ${ }^{1}$ Tomsk polytechnic university, 634050 Tomsk, Russia
}

\begin{abstract}
The goal of the presented research is to perform numerical modelling of fuel low-temperature vortex combustion in once-through industrial steam boiler. Full size and scaled-down furnace model created with FIRE 3D software and was used for the research. All geometrical features were observed. The baseline information for the low-temperature vortex furnace process are velocity and temperature of low, upper and burner blast, air-fuel ratio, fuel consumption, coal dust size range. The obtained results are: temperature and velocity three dimensional fields, furnace gases and solid fuel ash particles concentration.
\end{abstract}

\section{Introduction}

Low-temperature vortex (LTV) combustion is a technology of combustion concept in furnace volume. A horizontal vortex presence is a principal difference of this technology from the conventional flame combustion. A horizontal vortex has a horizontal axis of symmetry parallel to furnace front wall due to additional blast through the ash hopper opening neck. The main vortex is forced to appear in bottom part of the furnace volume; smaller vortex appearance is possible in upper and mid part of the furnace volume what depends on boiler design.

\section{Object of study}

Aerodynamics of this technology increases active burning area which in its turn let to decrease maximum temperature in the furnace and improve environmental performance due to de-crease of nitrogen oxides output. The technology makes possible to use granular fuel grind with different burning characteristics. Low-temperature vortex technology provides more stable burning and deflagration. The technology might be carried on in conventional chamber furnace by its upgrade during general maintenance.

We chose P-49 boiler furnace of the Nazarovo power station for the research. A chosen furnace placing presumes: straight-flow burners' presence on front wall, double-nozzled bottom blast, two row of tertiary blast, and aerodynamic overhang on back wall.

* Corresponding author: kseniashcherbakova@gmail.com 
LTV furnace numerical model was made by means of FIRE-3D software which is based on modern approach and methods of mathematical formulation of complex physicochemical processes [1]. The researched boiler furnace is symmetric in width, all burners and air feeders are located in furnace fore-and-aft plane therefore the aerodynamic is plain as well (parallel to side wall). Hence, it is reasonable to use only part of the furnace volume for the modeling instead of the full volume. Figure 1 shows longitudinal and cross section of the model.
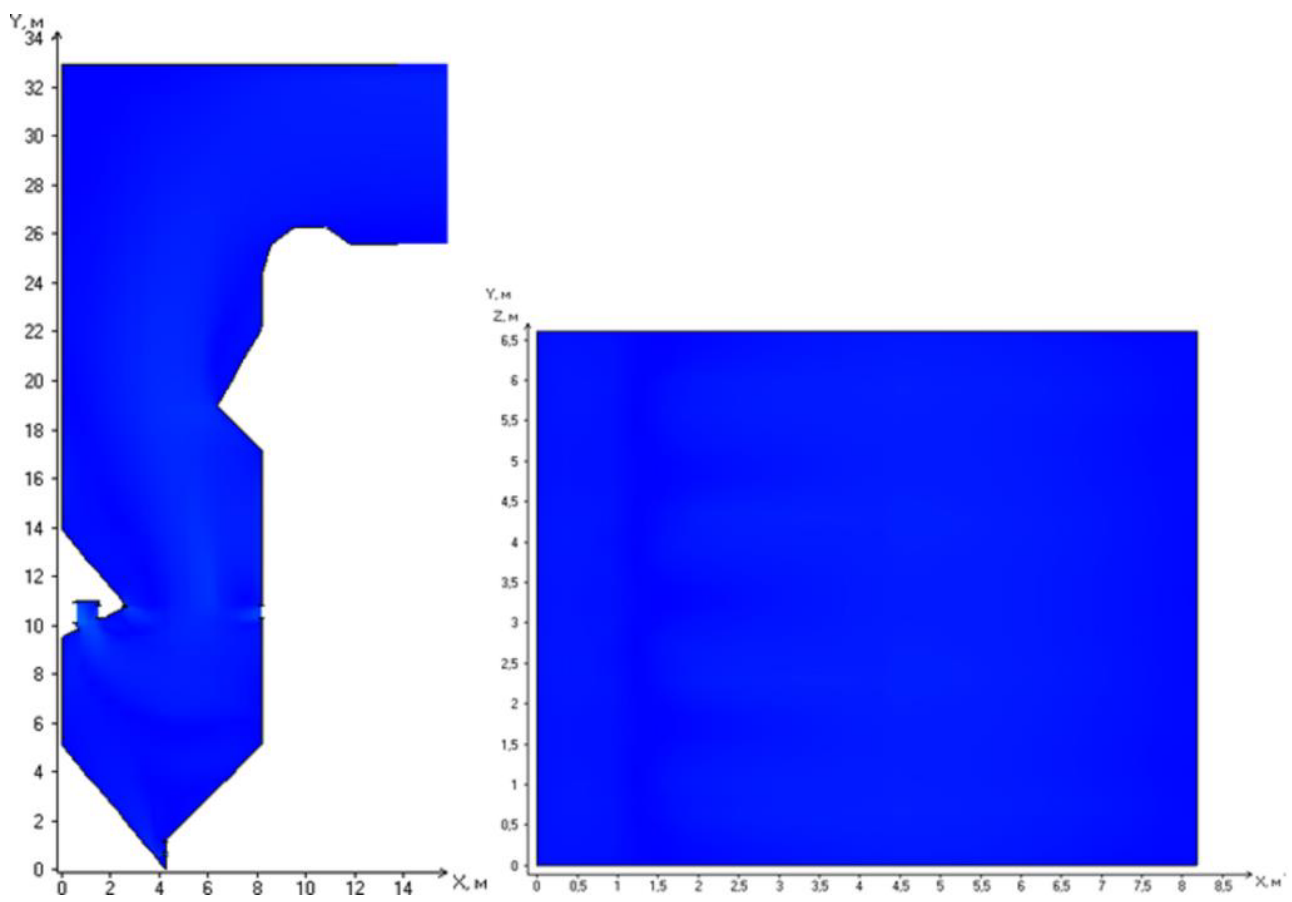

Fig. 1. Longitudinal (XY) and cross section (XZ) of the reduced size furnace.

The obtained model is used for processes research inside the furnace when Nazarovo brown coal is burned. Centrally directed pulverizing system is used for the boiler. That is why dry coal with the following characteristics is used as a base coal dust.

\section{Coal dust size range}

A coal dust size analysis results (Fig.2) show that researched coal dust consist mainly of 90 and $200 \mu \mathrm{m}$ (micrometers) coal dust particles, and then smaller fractions. Particles with size more than $500 \mu \mathrm{m}$ take not more than $6 \%$ of coal dust mass. Nominal condition fuel consumption is $41 \mathrm{~kg} / \mathrm{s}$ per boiler or $3.417 \mathrm{~kg} / \mathrm{s}$ per burner.

Presence of 5 coal dust fractions let us to model fuel dispersiveness with high accuracy. Fuel dust size increase - more than $55 \%$ of particles with size over $200 \mu \mathrm{m}$ - improve vortex area aerodynamic due to better two streams interaction. First stream formed by fuelair mixture; second stream consist of tertiary blast hot air. Streams are opposed one another and form force couple which creates vortex movement in the furnace bottom area. 


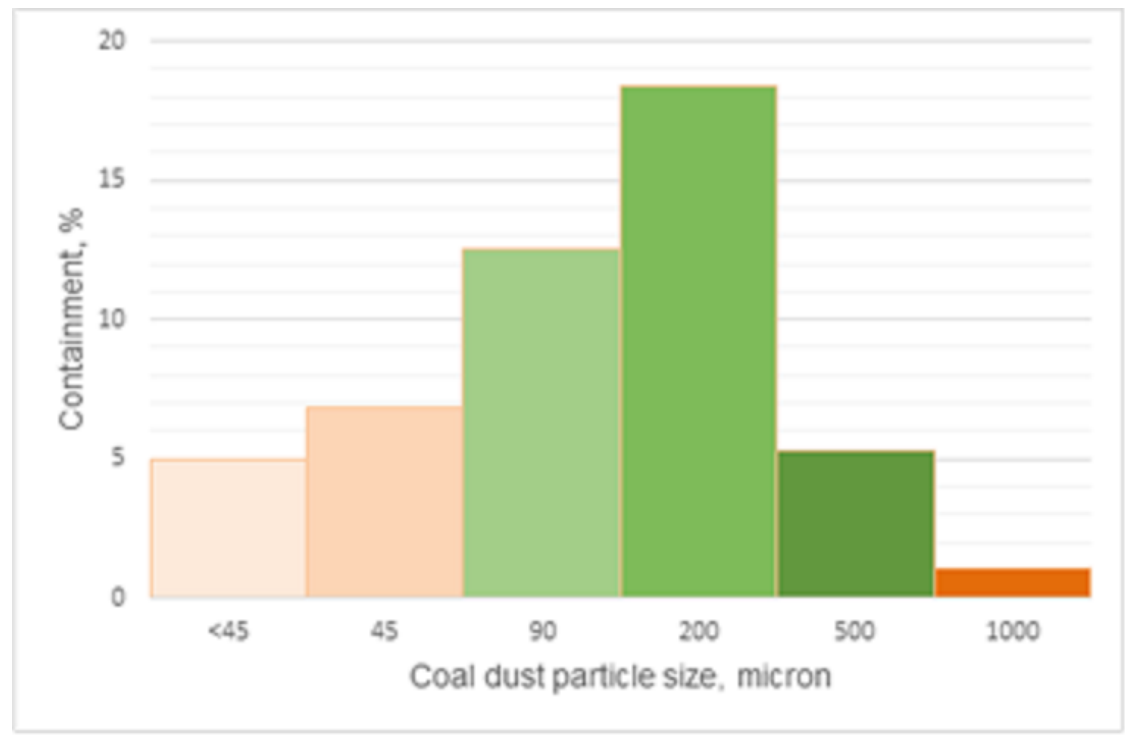

Fig. 2. Coal dust size analysis results.

\section{Air regimes}

Three different air regimes were calculated in order to re-search how bottom blast velocity influence. Burner blast re-mains constant - $50 \mathrm{~m} / \mathrm{s}$. Existing LTV boiler numerical model is used for the calculations [2].

Table 1 shows bottom blast velocity and models air regimes.

Table 1. Air regimes for evaluation of bottom blast velocity influence.

\begin{tabular}{|c|c|c|c|}
\hline \multirow{2}{*}{ Parameters } & \multicolumn{3}{|c|}{ Regimes } \\
\cline { 2 - 4 } & $\mathrm{a}$ & $\mathrm{b}$ & $\mathrm{c}$ \\
\hline Primary blast, $\omega_{1}, \mathrm{~m} / \mathrm{s}$ & 50.00 & 50.00 & 50.00 \\
\hline Secondary blast, $\omega_{2}, \mathrm{~m} / \mathrm{s}$ & 50.00 & 50.00 & 50.00 \\
\hline Bottom blast, $\omega_{3}, \mathrm{~m} / \mathrm{s}$ & 30.00 & 40.00 & 50.00 \\
\hline excess air, $\alpha$ & 1.22 & 1.20 & 1.20 \\
\hline
\end{tabular}

The research resulted with the following: all three regimes show air blast process of burner blast by bottom blast. An upward current is formed in mid area of the furnace. When it interacts with the aerodynamic overhang the current is brought to rest, enters upper part of the furnace with lower speed, and leaves through convection shaft exit window.

High oxygen concentration is corresponds to places of air input in the furnace. There is almost no oxygen in area below burners' awning.

\section{Temperature and oxygen distribution}

During the numerical modelling we obtained new data and present it in graphs. Graphs show mean value of temperature and oxygen containment through furnace height, and their change when bottom blast velocity is changed. 


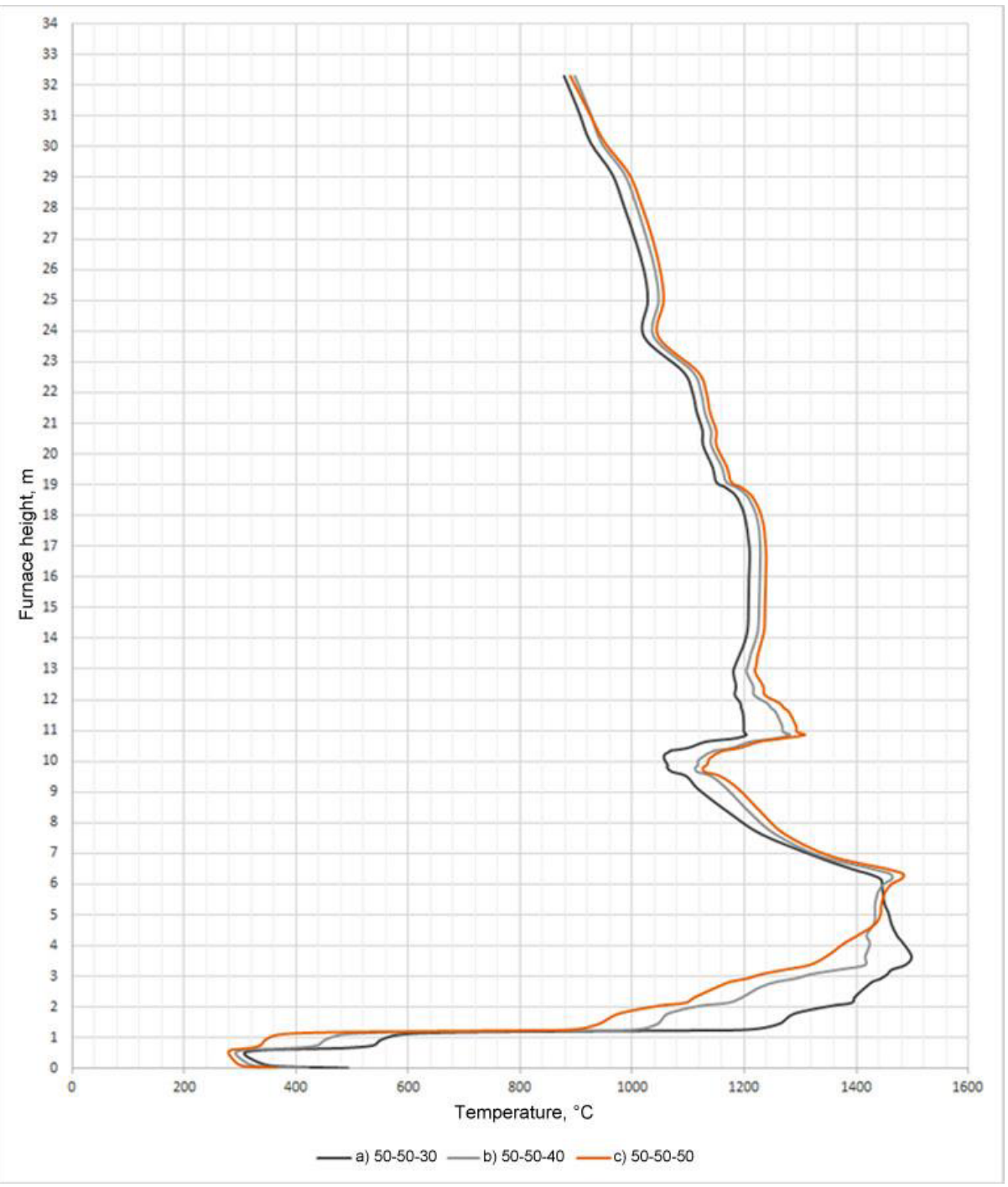

Fig. 3. Mean value of temperature through furnace height.

Temperature above burners' awning increase when bottom blast velocity is increased. This happens due to burning of particles which were thrown away from the vortex when bottom blast is increased. At the same time in the bottom area of the furnace gases temperature is lower because of cold air input through ash hopper opening neck. Oxygen containment through furnace height depends of velocity in the following way: the more bottom blast velocity, the more oxygen concentration because of the excess air presence. The excess air does not take part in combustion reaction on one condition - excess air was the same for all regimes. 


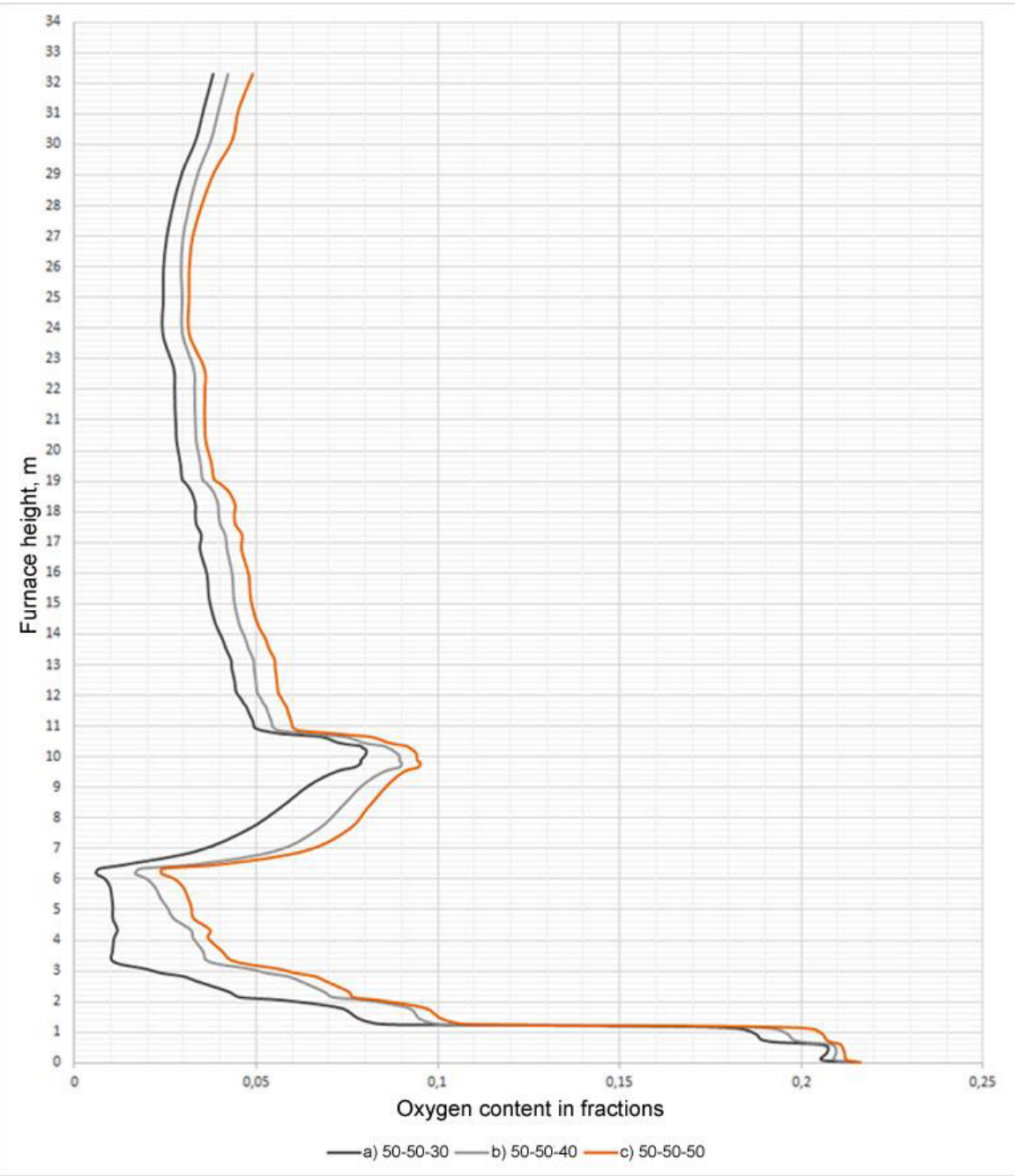

Fig. 4. Mean value of oxygen concentration through furnace height.

\section{Conclusion}

The conducted research shows how fuel size range affects burning processes of coombe brown coal in low-temperature vortex with horizontal rotation axis.

\section{References}

1. A.M. Bubenchikov, A.V. Starchenko, Numerical modeling of aerodispersive mixings' dymanic and combustion in channels, 221-234 (1998), ISBN 5-7511-1004-8 [In Russian].

2. P.S. Gergelizhiu, K.Y. Scherbakova, B.V. Lebedev, MATEC Web of Conf. 23, 01013 (2015) 